\title{
Marco general y tipología: la protección del patrimonio histórico como integrante del estatuto normal de la propiedad, su función social
}

Pedro Luis Roás Martin,

El patrimonio histórico y su protección se configuran en nuestro ordenamiento como intereses jurídicos fundamentales, cuya necesaria procura y consecución se impone a tenor del mandato que recoge el artículo 46 de la Constitución. En la órbita de los derechos e intereses de los particulares, la anterior premisa se traduce en importantes limitaciones y vinculaciones singulares que restringen, más allá de lo normal, el contenido esencial del derecho de propiedad; e, igualmente, en la imposición de un cúmulo de deberes de muy diversa naturaleza, que exceden de los de general observancia para los demás propietarios o titulares de derechos sobre bienes. De este modo, se hace recaer sobre los propietarios una gran parte del peso que implica la consecución de aquellos objetivos vinculados con la protección del patrimonio histórico.

Por ello, resulta exigible de las administraciones articular la aplicación de mecanismos que compensen en cierta medida aquellas mayores cargas y limitaciones, dado que se justifican éstas, en definitiva, en la obtención de unos fines que revierten en beneficio de la colectividad, debiendo ésta al amparo del principio de solidaridad, hacerse igualmente cargo del resarcimiento de tales sacrificios. Bajo tal premisa, se justifica en este concreto ámbito la aplicación de un sistema de responsabilidad patrimonial, que en gran medida pretende compensar daños derivados de actos plenamente

Palabras clave

Administración pública / Bienes de interés cultural / Compensación (Derecho) / Derecho de propiedad / Indemnización (Derecho) / Jurisprudencia / Patrimonio histórico / Propiedad privada / Protección / Responsabilidad patrimonial de la administración

\section{EL PATRIMONIO HISTÓRICO COMO INTERÉS JURÍDICO FUNDAMENTAL}

El patrimonio histórico debe configurarse como uno de los intereses jurídicos fundamentales de nuestro ordenamiento. Asi se deduce necesariamente del tenor con el que se expresa el artículo 46 de la Constitución, cuya correcta consideración exige, entre otros aspectos, conformar una marco adecuado de actividad administrativa orientada a lograr la consecución de objetivos vinculados por la protección eficaz de los diferentes bienes que lo integran, a fin de garantizar la puesta de los mismos a disposición de la colectividad (Tribunal Supremo, Sala de lo Contencioso-Administrativo, sección 7. a, sentencia de 6 de mayo de 2002).

Para ello, se hace preciso regular un conjunto de instrumentos de protección que, en gran parte, imponen deberes o cargas que exceden del cúmulo de facultades que generalmente integran la órbita del derecho de propiedad. Entre éstos, destacan todos aquellos supuestos en los que la presencia de un bien integrante del patrimonio histórico comporta la imposición de importantes vinculaciones o limitaciones singulares en orden a su conservación. Tal extremo suele traducirse en importantes restricciones al contenido normal del derecho de propiedad, que materialmente perjudican de un modo singular al titular de los anteriores o de cualesquiera otros relacionados con los mismos, haciendo surgir el deber de la comunidad de compensar dicho sacrificio, pues, en definitiva, se justifica éste en beneficio o interés de la generalidad.

Bajo tal perspectiva, qué duda cabe que resultan indicativos los efectos que se producen en las facultades del dominio, una vez que el bien es declarado de interés cultural o es incluido en algún inventario de protección (artículo 26 Ley 16/1985, de 25 de junio, del patrimonio histórico español). Así, en nuestro ámbito autonómico, resultan igualmente indicativas las consecuencias derivadas de la inscripción de los bienes en el Catálogo General del Patrimonio Histórico Andaluz, como se constata, entre otras, a partir de las previsiones contenidas en el artículo 11 de la Ley 14/2007, de 26 de noviembre, del patrimonio histórico de Andalucía. 
El escenario, por tanto, en el que se moverá este análisis atañe a las consecuencias o efectos derivados de la titularidad de determinados bienes, que revelan aquel interés, y que se constituyen en elemento verdaderamente identificativo de la normativa de protección del patrimonio cultural.

\section{EL PRINCIPIO DEL JUSTO EQUILIBRIO Y LA RESPONSABILIDAD PATRIMONIAL COMO UNA DE SUS CONSECUENCIAS}

Se hace preciso, por tanto, concluir, en primer término, que estamos en presencia de intereses jurídicos verdaderamente fundamentales y superiores respecto de otras posiciones juridicas singulares, y deben, en consecuencia, aquellos prevalecer en tal labor de ponderación, aún cuando ello exige igualmente la necesidad de considerar el deber de resarcir las importantes limitaciones y consecuencias perjudiciales que para el derecho de propiedad comportan.

\section{Límites al estatuto normal del derecho de propiedad. Proporcionalidad y justo equilibrio}

En el anterior contexto, las medidas limitadoras del dominio, impuestas a fin de proteger el patrimonio histórico, no han de ser exclusivamente soportadas por el sujeto titular de los bienes, sino que debe contribuir a ello toda la sociedad.

Idéntica justificación se ha hallado a fin de explicar la razón de las compensaciones que nuestro ordenamiento juridico reconoce en otros ámbitos diferentes, como pudiera ser el del urbanismo, en los que más allá de cualquier supuesto genérico de responsabilidad patrimonial, se pretenden compensar todos aquellos daños o perjuicios producidos al particular como consecuencia de la aplicación por la Administración de medidas que resultan plenamente acordes con el ordenamiento jurídico y con el uso que las mismas hacen de sus potestades en este ámbito. Se trata de la responsabilidad por actos jurídicos ilícitos, que sólo será viable en los casos en que exista una disposición legal que establezca la responsabilidad.

Se afirma, en el anterior sentido, que, por mucho que la responsabilidad patrimonial de la Administración sea objetiva, lo cierto es que la misma no es un seguro a todo riesgo. Esto se plasma, en el ámbito de la responsabilidad por hechos jurídicos, en la exigencia de que la relación de causalidad sea desde el punto de vista jurídico adecuada; de forma que en los casos en que el daño derive en exclusiva del hecho de tercero o de la culpa de la víctima, no hay responsabilidad patrimonial. Y, cuando de actos jurídicos se trata, lo que sucederá es que, salvo en los supuestos expresamente previstos por el ordenamiento, en caso de funcionamiento normal se tendrá el deber jurídico de soportar el daño (SSTS de 19 de octubre de 2004 o 5 de febrero de 2008). De lo contrario, cualquier acto administrativo desfavorable, por correcto que fuera (liquidación tributaria, sanción, denegación de licencia...), daría lugar a responsabilidad patrimonial; lo que obviamente no tiene sentido alguno (sentencia de la Sala de lo Contencioso-Administrativo del Tribunal Superior de Justicia de la Comunidad Valenciana de fecha 5 de diciembre del año 2008).

Esta tesis conduce a la idea relativa de que sólo en los supuestos expresamente contemplados en la ley se podrá generar un derecho de resarcimiento en caso de funcionamiento normal de la Administración, pues sólo la lesión producida en dichos supuestos tendrá naturaleza resarcible (carácter antijurídico del daño). Idea que adquiere una especial trascendencia en el contexto de la actividad protectora de las administraciones públicas, cuando del patrimonio histórico se refiere, en el que resultan amplísimas las facultades públicas a fin de regular el uso de los bienes con arreglo al interés general; y, en relación con la propia función social inserta en el derecho de propiedad (artículo 33.2 de la Constitución).

Sin embargo y más allá de los supuestos urbanisticos, en este ámbito de la protección del patrimonio histórico se hace posible concluir en una ampliación de las responsabilidades propias de las administraciones a la hora de indemnizar las consecuencias negativas derivadas de la imposición de vinculaciones y limitaciones singulares en la propiedad privada. Casos en los que, sin estar específicamente contemplado en una disposición legal, se puede llegar a entender que el particular soportó una carga desproporcionada y excesiva, que resultaba incompatible con el propio contenido esencial de su derecho de propiedad y que imponía, en definitiva, el deber de compensar, aún cuando el mismo no se hallare expresamente previsto en la norma legal aplicable.

Lo anterior ha sido reconducido a los parámetros propios del principio de proporcionalidad de la actividad administrativa, bajo la denominación del justo equilibrio, cuya aplicación recoge, entre otras, la sentencia del Tribunal Europeo de Derechos Humanos de 5 de enero del año 2000, en el caso Beyeler contra Italia, o nuestro Tribunal Supremo, en su sentencia de 9 de abril del año 1992.

Así, se razona, en el anterior sentido, que las medidas limitadoras de dominio no tienen por qué ser soportadas exclusivamente por el sujeto titular de los bienes, sino que a ello debe contribuir toda la sociedad y que nadie puede ser privado de su propiedad más que por causa de utilidad pública y en las condiciones previstas por la ley y los principios generales del derecho internacional. Y, sobre todo, tomando en cuenta el artículo primero del protocolo adicional al Convenio Europeo para la Protección de los Derechos Humanos y de las Libertades Fundamentales, que reconoce que toda persona física o juridica tiene derecho al respeto de sus bienes.

Bajo tal perspectiva y como se ha destacado, resulta cierto que los Estados tienen el derecho a poner en vigor las leyes que juzguen necesarias para la reglamentación del uso de los bienes, de acuerdo con el interés general o para garantizar el pago de impuestos $u$ otras contribuciones o multas, pero las injerencias en la propiedad privada deben adecuarse a un justo equilibrio. 
En el anterior sentido, se llega a concluir en el supuesto analizado en la primera de las sentencias mencionadas, que el ejercicio del derecho de tanteo llevado a cabo por el Estado italiano, y aún cuando se hallara expresamente previsto en una ley de dicho pais, constituía en la aplicación de que había sido objeto una medida indiscriminada que debía ser compensada en alguna forma.

En definitiva, se erige el justo equilibrio como manifestación del principio de proporcionalidad entre las exigencias del interés general de la comunidad y los imperativos de la protección de los derechos fundamentales del individuo $y$, si bien las administraciones gozan de un cierto margen de apreciación a la hora de identificar en cada supuesto lo que constituye el interés general de la comunidad, la aplicación concreta de tal manifestación debe ser interpretada en el marco de aquel principio de proporcionalidad y condicionada por el respeto al principio de legalidad y de la interdicción de la arbitrariedad de los poderes públicos.

\section{La responsabilidad patrimonial. Inexistencia de un sistema específico}

Ejemplo paradigmático de lo que se ha dicho es la sentencia del Tribunal Supremo de 25 de junio del año 2003, que resuelve un recurso de casación frente a una sentencia dictada por la Sala de lo Contencioso-Administrativo de Sevilla el 21 de febrero del año 2000, cuyo objeto giraba en torno a la desestimación presunta por parte de la Consejería de Cultura de la Junta de Andalucia de una reclamación de responsabilidad solicitada por razón de las limitaciones impuestas en un proyecto de edificación de trece viviendas y un garaje en la localidad Écija, pues durante la ejecución de la obra aparecieron restos del anfiteatro Astigi.

El fundamento de la reclamación radicaba en la importante limitación de la edificabilidad de una obra como consecuencia de las excavaciones arqueológicas previas a la obra de nueva planta y que se traducian en la imposibilidad concreta de edificar una planta sótano, debiendo los restos del anfiteatro ser integrados en la edificación, con respeto a las trazas del mismo.

Bajo tal escenario, se erigía en parámetro legitimador de la actividad administrativa cuestionada el artículo 50 de la Ley del patrimonio histórico de Andalucia, que establece la posibilidad de paralización de los trabajos por un plazo máximo de dos meses y sin derecho de indemnización; sólo cuando la paralización fuere superior, lo que en aquel caso no había sido acreditado, cabría la reparación. Además, era argumento esgrimido por la Administración el que la licencia fue concedida con las limitaciones impuestas por la legislación protectora del patrimonio histórico.

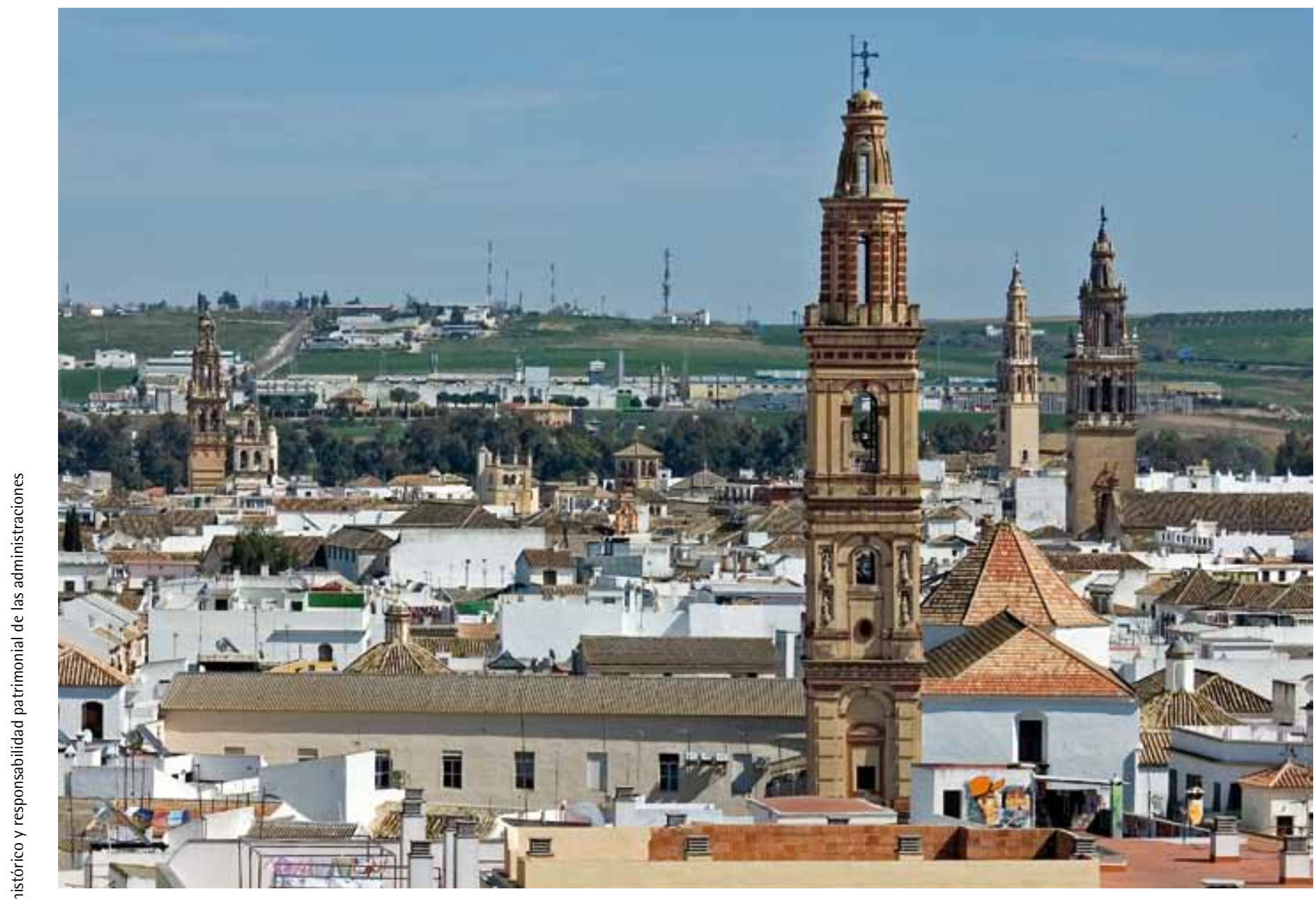

La sentencia del Tribunal Supremo en 2003 resuelve el derecho indemnizatorio del constructor de varias viviendas en Écija (Sevilla) tras la aparición de los restos del anfiteatro. Foto: Fondo Gráfico IAPH Uavier Romero García) 
Pues bien, a pesar de la citada cobertura normativa, la Sala de Instancia consideraba probada la existencia de limitaciones a la edificabilidad en la forma ya descrita; esto es, la imposibilidad de hacer una planta sótano y el deber de integración de los restos arqueológicos hallados. Y, con arreglo al artículo 43 de la entonces aplicable Ley 6/1998, de 13 de abril, sobre régimen del suelo y valoraciones, aquella situación se traducia en la necesaria apreciación de un supuesto indemnizatorio, de naturaleza urbanística, bajo la premisa de la existencia de una vinculación o limitación singular en orden a la conservación de edificios, que llevaba consigo una restricción del aprovechamiento urbanístico del suelo y que no podia ser objeto de una distribución equitativa entre los interesados.

En este supuesto, por tanto, se suscita el que la infracción de la normativa urbanistica aplicable, a partir del precepto anteriormente aplicado, sólo resultaba considerable para las disminuciones de aprovechamiento urbanístico derivadas de la ordenación urbanistica, que, en el supuesto examinado, no concurrió, ni derivaba de la misma, pues la disminución se producía como consecuencia de la aplicación de la normativa sobre conservación y protección del patrimonio histórico. Y, como consecuencia de lo anterior, la ausencia en nuestro ordenamiento de parámetros normativos que justificasen el reconocimiento de un derecho indemnizatorio a fin de compensar los perjuicios o daños derivados de aquellas limitaciones o vinculaciones singulares, cuando las mismas se hallaban justificadas en razones sustancialmente diversas a las propias y derivadas de la ordenación urbanística.

En la sentencia citada se llega a la conclusión de que los preceptos contenidos en las normas urbanisticas acerca de los supuestos indemnizatorios derivados de limitaciones y vinculaciones singulares tienen restringido su ámbito de aplicación a dicho contexto, dada la ubicación sistemática de tales preceptos, la expresa indicación en los mismos a restricciones derivadas de ordenación y régimen jurídico de suelo, así como a la aplicación de técnicas propias del ordenamiento urbanistico, como la equidistribución entre los interesados, que no resultarían aplicables al ámbito de la protección del patrimonio histórico. Sin embargo, se concluia igualmente que tal circunstancia no debe llevar a desconocer la existencia de mecanismos adecuados en nuestro ordenamiento a fin de compensar la citada situación en este exclusivo ámbito.

Bajo tal consideración, razonaba el Tribunal Supremo que, en relación con la protección del patrimonio histórico, un eventual derecho de indemnización sólo tendría su fundamento en la normativa general sobre responsabilidad patrimonial de la Administración Pública (artículos 139 y siguientes de la Ley 30/1992, de 26 de noviembre, sobre régimen jurídico de las administraciones públicas y del procedimiento administrativo común) o, en su caso, en la normativa sobre expropiación forzosa. Con ello, el Tribunal Supremo realizaba una auténtica proclamación de la aplicabilidad del sistema de responsabilidad general al ámbito de la protección del patrimonio histórico y, a partir de la prueba practicada, con- cluia que, en el supuesto concreto objeto de análisis, el reclamante sufrió una restricción del aprovechamiento urbanistico que correspondia a su terreno, derivada de la normativa de protección y conservación del patrimonio histórico y que, si bien se trataba de una restricción o lesión legítima, la misma estaba establecida en beneficio de la colectividad, no estando, por ello, el actor obligado a soportar a expensas de su solo patrimonio tal circunstancia.

Se trata, en definitiva, de un supuesto de responsabilidad patrimonial de la Administración, cuyo análisis exige la valoración de los requisitos que con carácter general se exigen para apreciar un supuesto de esta naturaleza en cualquier otro ámbito propio de las administraciones públicas y de su funcionamiento y que llevó a considerar, en este caso, que el particular no debió soportar exclusivamente la lesión en beneficio de toda la colectividad, por lo que resultaba justo que fuere recompensado mediante el pago de la correspondiente indemnización.

En definitiva y como primera conclusión, es posible destacar que la práctica de los tribunales viene a configurar el régimen de la responsabilidad patrimonial que se ofrece en este ámbito de un modo sustancialmente idéntico al propio del sistema general existente en la materia; esto es, se genera la responsabilidad patrimonial en dicho ámbito en todos aquellos supuestos en los que el administrado sufre una lesión patrimonial, consecuencia directa del obrar, correcto o no, de la Administración y, así, surge la procedencia de la indemnización.

Procede, en definitiva, el examen en cada caso concreto de la concurrencia de los requisitos generales para apreciar un supuesto constitutivo de responsabilidad patrimonial, con el consiguiente nacimiento del derecho del particular a obtener una indemnización por los daños producidos y derivados de la actividad administrativa correspondiente. Habrá que estar, en cada supuesto, al análisis de la necesaria concurrencia de los requisitos que nuestra jurisprudencia viene exigiendo a tal fin y que pueden sintetizarse como sigue:

a) Producción, por acción u omisión, de una lesión patrimonial antijurídica y por tanto, resarcible. Esta lo será cuando el particular no tenga el deber de soportar un daño que sea imputable a la Administración, lo que ocurrirá cuando lo ocasione un agente de ésta, actuando en el ámbito de sus competencias, incluso cuando la acción originada es ejercida legalmente, pues cualquier conducta dañosa debe ser en principio indemnizada porque de otro modo se produciria un sacrificio individual a favor de una actividad de interés público, que en algunas ocasiones debe ser soportada por la comunidad.

b) El perjuicio, daño emergente o lucro cesante, debe ser efectivo, concreto, individualizado, y evaluable económicamente, sin que concurran causas de justificación que exoneren a la Administración, entre las que cabe citar sólo la fuerza mayor y la conducta del propio recurrente, si es determinante de la producción del daño. 
c) Carácter objetivo de la responsabilidad, sin que sea exigible realizar una referencia a la culpa del agente, pues la Administración responde del mal funcionamiento normal o anormal, de los servicios públicos, aunque el daño se produzca de forma involuntaria o como consecuencia del riesgo en la prestación de ciertos servicios. Ni siquiera es preciso probar que el servicio público se ha desenvuelto de manera anómala, bastando que el riesgo inherente a su utilización haya sobrepasado los límites impuestos por los estándares de la seguridad exigibles conforme a la conciencia social. En definitiva, se trata de socializar los riesgos cuando se actúa en defensa de los intereses generales lesionando los particulares. d) Que exista relación directa de causalidad entre el daño y la actuación de la Administración, pues el hecho que origina el daño debe ser en si mismo idóneo para ocasionarlo. La relación de causalidad debe entenderse en el marco de la responsabilidad objetiva, por lo que, como queda dicho, sólo la fuerza mayor y la conducta dolosa o negligente del propio recurrente, si es determinante de la producción del daño, pueden romper el nexo causal. e) Que se entable la reclamación dentro del año siguiente al momento de la causación de los perjuicios.

\section{Algunas singularidades propias de la protección del patrimonio histórico en el marco de la responsabilidad patrimonial de las administraciones públicas}

Es empero en aquellos casos en los que se genera un daño en caso de funcionamiento normal de la Administración donde se hallan más especialidades en esta materia, debiendo ser objeto de análisis en cada supuesto concreto la naturaleza de la lesión producida y, sobre todo, su carácter resarcible (carácter antijurídico del daño).

Como se ha expuesto y en relación con la protección del patrimonio histórico, el ordenamiento define el contenido esencial del derecho de propiedad mediante la imposición de importantes deberes que restringen sustancialmente las amplias facultades que tradicionalmente integran aquél. Es precisamente éste otro de los ámbitos en el que vierte su eficacia la tesis anteriormente indicada acerca del deber de resarcimiento por parte las administraciones públicas en orden a distribuir equitativamente entre la colectividad los perjuicios derivados de aquellas mayores cargas, cuya definitiva observancia se orienta, en definitiva, a la defensa y consecución de intereses generales.

En relación con estos deberes, destacan los de conservación que, con carácter general señala el artículo 36.1 de la Ley del patrimonio histórico español, cuyo alcance es especialmente intenso pues conlleva el deber de observancia y desarrollo de actuaciones positivas a los propietarios particulares, orientadas a la guarda y mantenimiento de la cosa. Así, el anterior precepto señala que los bienes integrantes del patrimonio histórico español deberán ser conservados, mantenidos y custodiados por sus propietarios o, en su caso, por los titulares de derechos reales o por los poseedores de tales bienes. Y, en el mismo sentido, la Ley del patrimonio his- tórico andaluz, en su artículo 14.1, que dispone que las personas propietarias, titulares de derechos o simples poseedoras de bienes integrantes del patrimonio histórico andaluz, se hallen o no catalogados, tienen el deber de conservarlos, mantenerlos y custodiarlos de manera que se garantice la salvaguarda de sus valores.

Se articula, por tanto, la anterior relación de deberes como una limitación común, consistente en obligaciones positivas o de hacer, que además enlazan directamente con el mandato incorporado en el artículo 46 de nuestra Constitución.

Por lo demás y en orden a garantizar el efectivo cumplimiento de las anteriores obligaciones, regula en nuestro ámbito autonómico el artículo 15.1 de la Ley del patrimonio histórico andaluz las órdenes de ejecución. De este modo y en el marco de los mecanismos de ejecución forzosa propios de la Administración Pública, señala el anterior precepto que la Consejería competente en la materia podrá ordenar a las personas propietarias, titulares de derechos o simples poseedores de bienes inscritos en el Catálogo General del Patrimonio Histórico la ejecución de obras o la adopción de las actuaciones necesarias para su conservación, mantenimiento y custodia; previsión que, por otra parte, desarrolla la premisa básica que aparece igualmente descrita en los apartados tercero y cuarto del artículo 36 de la Ley del patrimonio histórico español. Llega incluso este último precepto más lejos, al señalar que cuando los propietarios o titulares de derechos reales sobre bienes declarados de interés cultural o incluidos en el Inventario General no ejecuten las actuaciones exigidas en cumplimiento de las obligaciones de conservación y mantenimiento descritas, la Administración competente, previo requerimiento, podrá ordenar su ejecución subsidiaria, añadiendo que podrá realizar también de modo directo las obras necesarias, si así lo requiere la más eficaz conservación de los fines. Más aún, destaca el apartado cuarto que el incumplimiento de estas obligaciones puede ser causa de interés social a fin de justificar el ejercicio de la potestad expropiatoria en este supuesto.

En el marco de lo expuesto y con arreglo al artículo 46 de la Constitución, integran los deberes dominicales derivados de la titularidad de bienes integrantes del patrimonio histórico o de derechos reales sobre los mismos un conjunto de obligaciones vinculadas directamente con el deber activo de conservación, mantenimiento y custodia que puede llevar a considerar, incluso, que provoca el revestimiento a los particulares con facultades propias de la potestad administrativa de policía.

Esta cuestión ha sido caracterizada aún como determinante de la atribución al propietario de una cierta potestad funcionarial de policia, que se añade al nivel de observancia normal de los propietarios en relación con sus deberes de conservación y mantenimiento de los bienes. Véase, en el anterior sentido, que la regulación que se hace en la leyes de patrimonio histórico español y andaluz acerca de las infracciones en la materia se describen algunos tipos vinculados precisamente con el incumplimiento de tales obligaciones, 


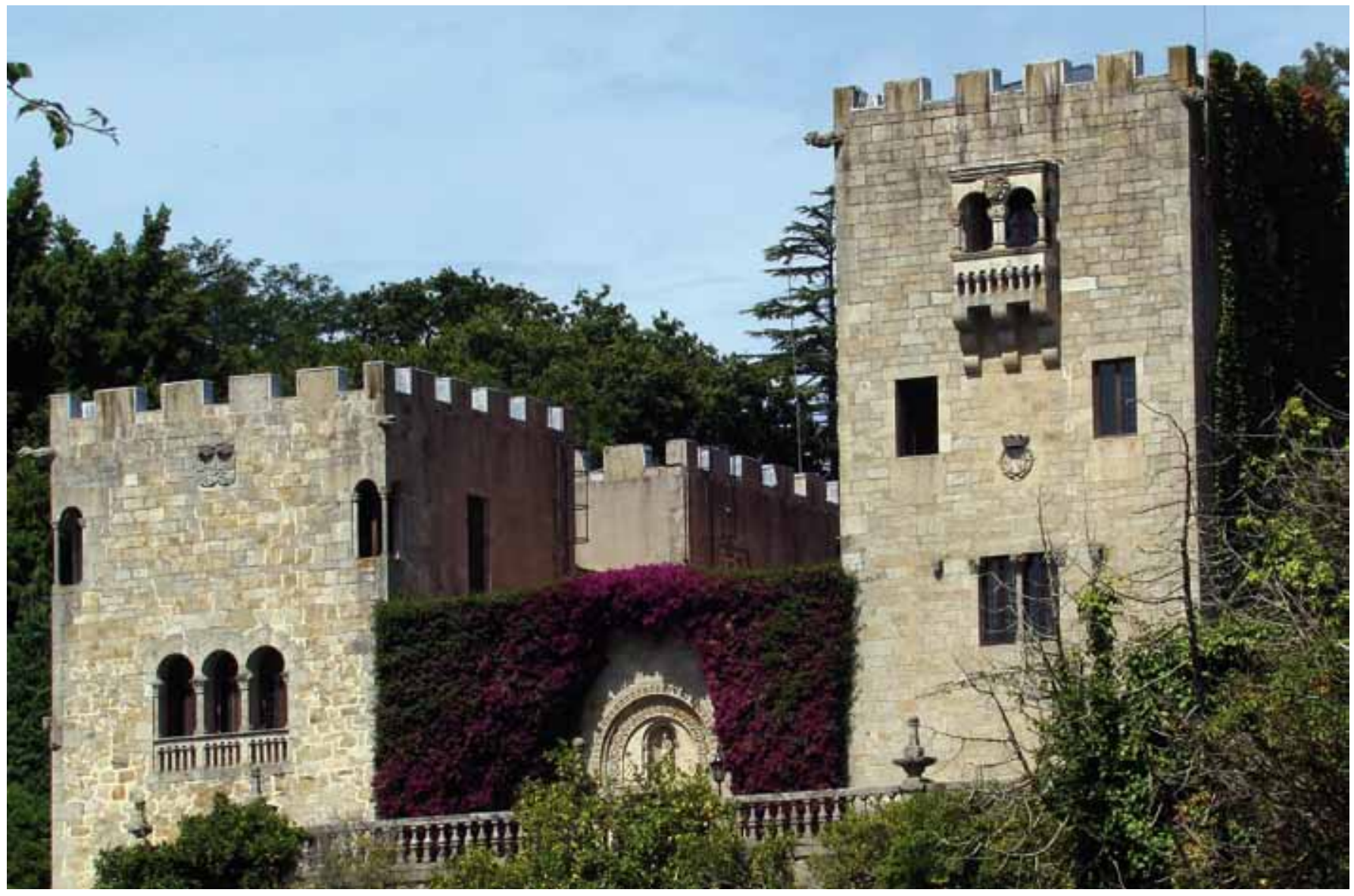

El pazo de Meirás (A Coruña) es un caso típico de conflicto entre el interés colectivo que lleva asociado cada BIC declarado y la propiedad privada que impide su visita pública. Foło: Mercedes Blanco

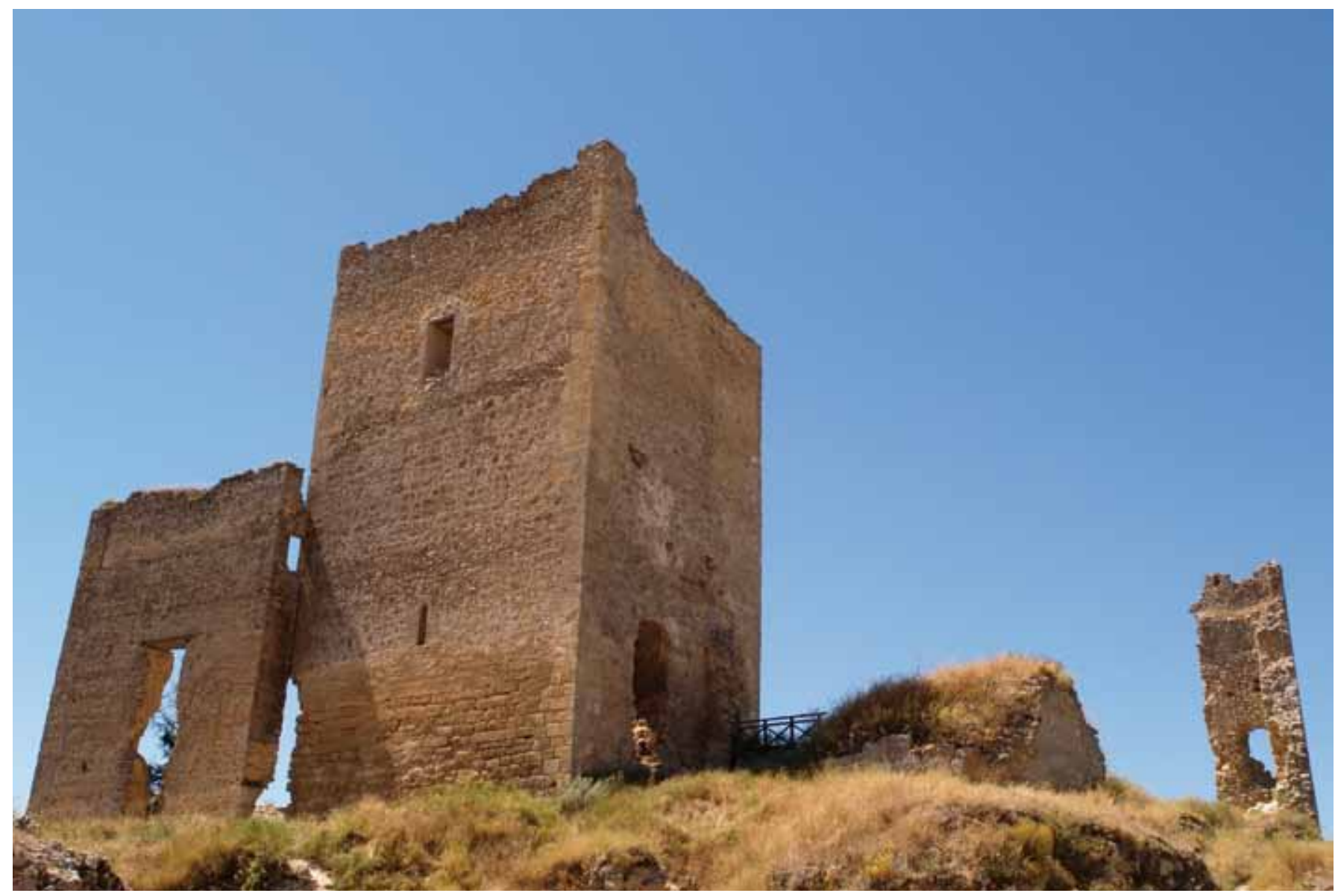

La responsabilidad patrimonial de las administraciones se extiende por la omisión de sus deberes en el mantenimiento de los bienes, como en el caso del castillo de Calatañazor (Soria) en el que el desprendimiento de una piedra provocó el fallecimiento de una persona. Foto: Manolo Blanco 
lo que se traduce de una manera efectiva en un añadido de los deberes del propietario cuando se trata de estas obligaciones de mantenimiento y custodia (artículo 76 LPHE y 108-110 LPHA).

Pues bien, en lo que hace al presente análisis, no es posible obviar que la mayor intensidad del cúmulo de deberes que definen el contenido del derecho de propiedad, cuando de bienes integrantes del patrimonio histórico se trata, tiene por objetivo la satisfacción de intereses generales vinculados con la protección de los mismos y su adecuada conservación a fin de permitir su disfrute colectivo y puesta a disposición de la comunidad. No resulta, por tanto, posible considerar que, a pesar de la plena legalidad de la solución descrita, el propietario singular soporte exclusivamente las consecuencias negativas o perjudiciales de la observación de tales deberes, que vienen, en definitiva, a restringir considerablemente el contenido normal del derecho de propiedad. Se hace preciso por ello articular igualmente soluciones resarcitorias que compensen, en definitiva, ese mayor sacrificio individual y consigan revertir sobre el conjunto de la colectividad el alcance de las meritadas cargas.

Se plantea ahora la referida cuestión y alcance de la responsabilidad patrimonial de las administraciones con cierta singularidad, pues, en relación con la imposición de los citados deberes de conservación, custodia y mantenimiento, la intensidad de tales cargas, superiores a los generales deberes de observancia propios del derecho de propiedad, se constata de un modo especialmente evidente.

En primer término, en la medida que los deberes de conservación, custodia y mantenimiento, además de la atribución de una posición activa predicable individualmente del titular de los bienes y derechos, arroja igualmente una obligación de uso y aprovechamiento del bien conforme los valores que aconsejan la conservación.

De este modo, se pronuncia el apartado segundo del ya citado artículo 36 de la Ley del patrimonio histórico español, cuando señala que la utilización de los bienes declarados de interés cultural, así como de los bienes muebles incluidos en el Inventario General, quedará subordinada a que no se pongan en peligro los valores que aconsejan su conservación. Cualquier cambio de uso deberá ser autorizado por los organismos competentes para la ejecución de esta ley.

Es evidente que la primera consecuencia del deber de conservación es indudablemente que el uso del bien no puede conllevar su destrucción o deterioro, pero la definición de la anterior obligación ofrece un alcance superior, pues obliga a identificar, en primer término, la conveniencia o no del uso de los bienes; $y$, en segundo lugar, la adecuación o entidad de dicho aprovechamiento en función de las circunstancias de cada caso.

En relación con lo expuesto, se plantea un amplio debate técnico acerca del alcance de las actuaciones de restauración y rehabilitación que igualmente podrian formar parte de aquellos deberes de conservación y mantenimiento. Polémica de la que se hacen eco algunas sentencias de nuestros tribunales, como la de 16 de octu- bre del año 2000 del Tribunal Supremo, cuyo objeto giraba en torno a la adecuación del proyecto de restauración y rehabilitación del teatro romano de Sagunto. Se suscitaba sobre el citado proyecto que, desde los años 50, el teatro había recuperado durante el verano su función propia, así como la de albergar espectáculos de diferente orden, siendo la percepción que del monumento podía tener hoy el visitante cuando menos confusa, sino engañosa. En concreto, se analizaba si las diferentes intervenciones a la que el mismo había sido sometido parecian haber tenido, como objetivo principal, no la restitución del teatro tal como era, sino más bien la ruinas en sí mismas, convirtiéndose el proyecto, a todo los efectos, en el proyecto de un teatro a la manera de los antiguos romanos. En el marco de esta controversia, de alcance indudablemente técnico, se identifican en la sentencia dos tipos de límites aplicables y exigibles en el marco de los deberes de conservación, consolidación y rehabilitación, siendo fundamental la proscripción de los intentos de reconstrucción, en la forma que señala el apartado segundo del artículo 39 de la Ley del patrimonio histórico español.

Y, en el mismo sentido, la sentencia del Tribunal Supremo de 13 de mayo de 2008, sobre el proyecto básico de ejecución y rehabilitación de la muralla de Cartagena, en el tramo comprendido entre los Héroes de Cavite y Cuba y el hospital de Marina, con ocasión de la contemplada supresión del balaustre de la muralla y colocación de un antepecho en su sustitución.

\section{La práctica de nuestros tribunales. Algunos ejemplos}

No obstante, aparte de supuestos como los más arriba referidos que entrañan un importante ámbito de valoración de la discrecionalidad desplegada en las diferentes soluciones técnicas aprobadas por la Administración, la incorporación de un cúmulo de deberes superiores a los generales de observancia en la conservación y mantenimiento de los bienes que integran tradicionalmente el derecho de propiedad, se exhibe destacadamente cuando tales limitaciones alcanzan a los aprovechamientos singularizados de los que resulta propia la cosa o el bien en función de su naturaleza.

Así, la sentencia de la Sala de lo Contencioso-Administrativo del Tribunal Superior de Justicia de Extremadura 19 de septiembre del año 2002, que analiza la conformidad a derecho de un requerimiento formulado por parte de la Administración autonómica competente a los propietarios de un terreno, a fin de que en el plazo de un mes procediesen a recubrir las estructuras arqueológicas dañadas con motivo de unas obras de explanación de unos terrenos existentes en una finca. Se analiza en esta resolución judicial el supuesto relativo a la aparición de unos restos arqueológicos durante unos trabajos de nivelación que se habian acometido en unos terrenos de tres parcelas rústicas; restos cuya presencia fue denunciada de modo anónimo. Tras la práctica de una actividad de inspección por parte del personal técnico competente, se puso de manifiesto que en la finca de referencia se habían realizado trabajos de nivelación que habían provocado la destrucción de una gran cantidad de restos ar- 
queológicos que podian ser atribuidos a una villa de cronología altoimperial con posibles prolongaciones en época tardorromana y que los elementos destruidos lo fueron intencionalmente a juicio de los funcionarios actuantes.

Con independencia de estas últimas consideraciones, el informe emitido por los servicios de la Consejería concluía que la conservación de los restos resultaba incompatible con la explanación de los terrenos, proponiéndose que las estructuras arqueológicas dañadas se cubrieran en toda su extensión y se prohibiese la realización de trabajos de explanación o montaje de instalaciones de riego subterráneas, así como todos los actos de laboreo que implicasen roturaciones profundas o siembras que pudiesen dañar el yacimiento cubierto.

En este contexto, se suscita la controversia relativa a si deben soportar los propietarios de las parcelas las limitaciones administrativas que se imponen sobre los terrenos para su protección; y, que además en este caso hacen imposible la continuación de las labores normales de cultivo que se venían desarrollando por parte de los interesados. De la misma forma, se admite la imposible realización de los trabajos de nivelación, de modo compatible con la conservación y protección de los bienes integrantes del patrimonio hallados en aquel lugar, a pesar de que aquella labor de nivelación resultaba necesaria por el riesgo de inundación.

Pues bien, en este supuesto y precisamente al amparo de los deberes de conservación, mantenimiento y custodia ya descritos, se pondera en la sentencia la inactividad de la propia Administración Pública a la hora de asumir directamente el deber de protección de tales bienes, llevando a cabo la declaración que resultare procedente a los efectos de aplicar el singular régimen de protección que correspondiera. Sin embargo, según se afirma, se opta por mantener la propia de los terrenos en poder de los propietarios, pero imponiéndoles una serie de limitaciones, con lo que se pretendería hacer recaer sobre los recurrentes propietarios de los terrenos el coste de la protección de los bienes descubiertos, que obtienen un claro beneficio en favor de la colectividad, sin recibir por ello los propietarios compensación alguna. Bajo tales consideraciones y con arreglo a la definición de los deberes de conservación y custodia ya descritos, en el marco de las previsiones contenidas en el artículo 36 de la Ley del patrimonio histórico español, el tribunal concluye en la plena conformidad a derecho de la exigencia impuesta, a través del requerimiento impugnado, a los propietarios de conservación de los bienes hallados y restricción sustancial, aún desaparición, de amplias facultades integrantes de su derecho de propiedad sobre los anteriores, pues impedía el aprovechamiento de los terrenos conforme a su propia naturaleza en orden a la consecución de los objetivos vinculados con la protección del patrimonio histórico. Más aún, se destaca la ausencia de una activa intervención por parte del Administración Pública a la hora de asumir directamente las labores de protección, defensa y conservación de tales bienes, haciendo recaer sobre los propietarios de los terrenos el cumplimiento y la plena satisfacción de las mencionadas cargas. Y todo ello, como se expone, en beneficio de la colectividad.
Por ello, se concluye en la necesidad de reconocer una indemnización de los daños y perjuicios ocasionados, derivados del imposible cultivo de los terrenos, a los propietarios, pues concurririan plenamente en este supuesto los requisitos necesarios a fin de apreciar una situación constitutiva de responsabilidad patrimonial de las administraciones.

En el mismo sentido, resulta indicativa la sentencia de la Sala de lo Contencioso-Administrativo de Granada del Tribunal Superior de Justicia de Andalucía, de 8 de noviembre del año 2004, en cuyo supuesto se analiza la procedencia de una indemnización de daños y perjuicios derivados de la declaración de bien de interés cultural, con la categoría de zona arqueológica, de un determinado yacimiento, que, en definitiva, impediria la actividad de extracción de mármol que se venía realizando en dicho lugar. En este caso, se constataba, a partir de la prueba pericial practicada, la imposibilidad de extraer material de la cantera sin actuar directamente en el perimetro señalado como zona arqueológica.

Al igual que en los anteriores supuestos, en este caso el tribunal se cuestiona acerca del deber del propietario de soportar exclusivamente la imposición de tales limitaciones, que se traduciría en una limitación real de sus facultades dominicales, haciendo recaer el coste de la protección a los propietarios, por lo que el mismo debiera ser indemnizable. A modo de sintesis, se puede concluir que en este supuesto, el tribunal identificaba la concurrencia de los requisitos precisos a fin de apreciar un supuesto constitutivo de responsabilidad patrimonial: lesión en los bienes propiedad de la reclamante; dicha lesión resultaba consecuencia del funcionamiento de un servicio público; la Administración competente actuó en aplicación de la normativa de aplicación del patrimonio histórico,

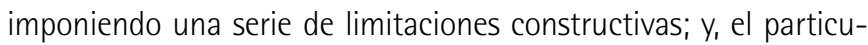
lar, no tenía el deber jurídico de soportar dicha lesión, pues toda la colectividad mediante el pago de indemnización debía contribuir, bajo el principio de solidaridad, a la compensación de tales cargas.

\section{LÍMITES AL ALCANCE DE ESTE RÉGIMEN DE RESPONSABILIDAD. CASUISMO Y PRUEBA}

A pesar de lo expuesto y al igual que ocurre en cualquier otro ámbito de nuestro sistema de responsabilidad, debe tomarse en cuenta que la Administración Pública no se constituye en una aseguradora absolutamente objetiva y universal que deba compensar la producción de cualesquiera daños y perjuicios generados en el patrimonio de los particulares. Además de resultar precisa la efectiva constatación en cada supuesto de la concurrencia de los requisitos ya descritos, se hace igualmente necesario comprobar la ausencia de otros factores o extremos que puedan romper el citado nexo de causalidad entre el daño, cuya indemnización se pretende, y el funcionamiento de los servicios públicos.

El relación con este último aspecto, resulta ilustrativa la sentencia que dictó el Tribunal Supremo el 24 de junio del año 2010, con 


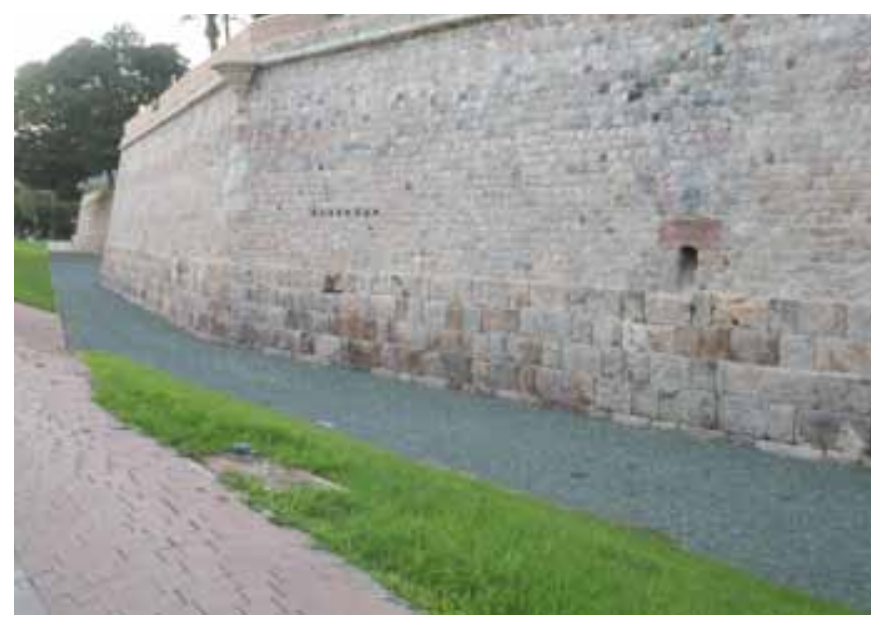

Ejemplo de responsabilidad patrimonial de las administraciones públicas en sus deberes de conservación y mantenimiento lo tenemos en las murallas de Cartagena. Foto: Vicente Ruiz (Valencia)

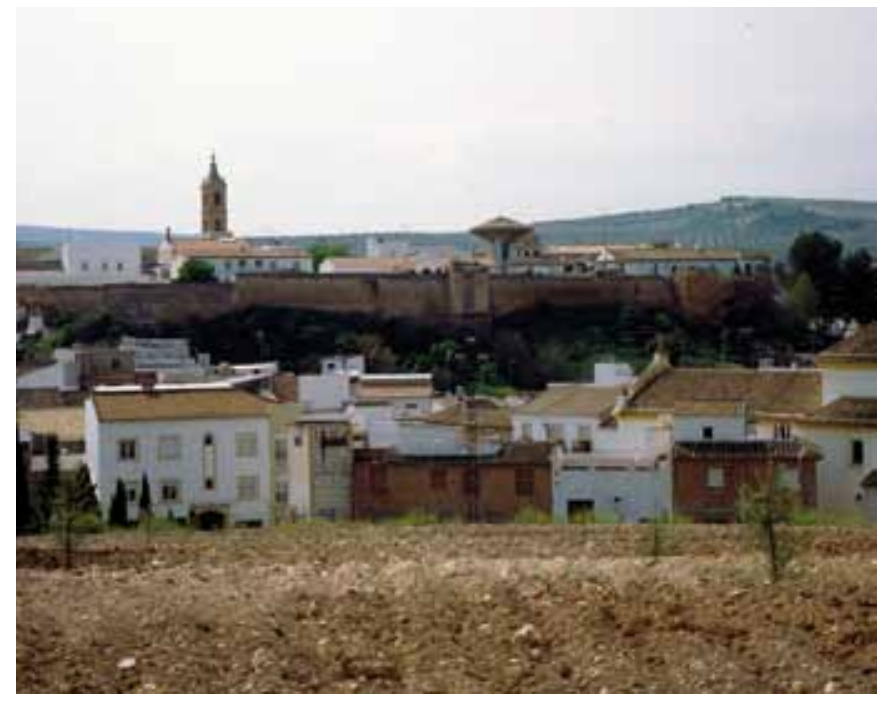

En el entorno del Castro del Río (Córdoba) se desestimó la petición indemnizatoria por los perjuicios urbanísticos provocados por la aparición de un yacimiento arqueológico. Foto: Fondo Gráfico IAPH (Fernando Alda)

ocasión de un supuesto vinculado con la desestimación presunta de una petición indemnizatoria de los perjuicios derivados de la pérdida de aprovechamiento urbanístico y limitaciones constructivas en determinadas parcelas situadas en la localidad de Castro del Río (Córdoba) y ante la presencia de un yacimiento arqueológico. En este caso, se concluye en la inexistencia de un daño antijurídico, esto es, el particular afectado tenía el deber de soportar, al amparo de la normativa propia de protección del patrimonio histórico y máxime cuando la intervención en aquel supuesto estuvo motivada por el incumplimiento de las obligaciones impuestas por la normativa urbanística dirigidas a la protección del patrimonio arqueológico existente la zona.

Es el anterior un supuesto en que el alto tribunal hace recaer sobre la culpa exclusiva del reclamante la causación de los daños ocasionados, no resultando, por tanto, éstos indemnizables. La declaración de impacto ambiental obrante en el proceso indicaba la obligatoriedad de someter a vigilancia arqueológica intensiva los movimientos de tierra en todo el ámbito del plan parcial exis- tente, especialmente en aquellas zonas donde fueren a producirse movimientos de tierra, que, además, debiera ser desempeñada por técnico competente, arqueólogo. Cualquier hallazgo casual de tipo arqueológico habría de ser comunicado inmediatamente a la Administración. Esta medida aparecia igualmente incorporada al planeamiento urbanístico de la localidad.

Pues bien, como consecuencia de los movimientos de tierra efectuados por la empresa reclamante, se perdió parte del yacimiento, acordándose la paralización y el desarrollo de una actividad arqueológica preventiva, consecuencia de la cual, se impusieron una serie de prescripciones, respecto a la conservación de los restos en las parcelas, a fin de articular deberes de conservación y no afección de los restos.

De este modo, el Tribunal Supremo concluyó que la actividad arqueológica preventiva, a la que se imputaban los daños cuya indemnización eran objeto de reclamación, se hallaba motivada precisamente por el incumplimiento por parte del promotor de la cautela arqueológica establecida en el planeamiento urbanístico, existiendo además en la normativa aplicable la previsión relativa a que la Administración se hallaba autorizada a fin de ordenar una intervención arqueológica de urgencia y de conservación de los restos hallados.

En definitiva, la construcción interpretativa que desarrolla el Tribunal Supremo en la anterior sentencia obliga a un análisis casuístico de los diferentes elementos materiales que concurren en cada supuesto y que permitan, en definitiva, ponderar si la conducta desplegada por parte del perjudicado puso de manifiesto una cierta negligencia o intencionalidad en la definitiva causación de la mencionada situación. Así, en este supuesto, el Tribunal Supremo analiza el deber jurídico de soportar las consecuencias de las medidas impuestas, a partir del conocimiento pleno que tenía el promotor de la inmediatez del yacimiento arqueológico, del contenido del planeamiento urbanístico, con las previsiones ya descritas, y de las cautelas arqueológicas introducidas, por tanto, en el mismo. Y, se concluía, por tanto, en la sentencia, "(...) De haberse actuado como imponía el planeamiento, es decir, poniendo en conocimiento de la Consejería de Cultura, los hallazgos arqueológicos, podría haberse evitado el daño que se produjo en el patrimonio histórico artístico que motivó incluso una condena penal, y también la actuación urgente que finalmente ha originado la reclamación de responsabilidad patrimonial (...)".

\section{LA RESPONSABILIDAD DE LA ADMINISTRACIÓN FRENTE A TERCEROS}

Los supuestos de responsabilidad patrimonial de las administraciones públicas, en el concreto ámbito de la protección del patrimonio histórico, no sólo se desenvuelven con ocasión de la imposición de limitaciones o vinculaciones singulares que exceden de los deberes de general de observancia de impuestos a los propietarios, sino que igualmente hallan su aplicación cuando de 
daños o perjuicios a terceros se trata. Esto es, supuestos en los que el daño es ocasionado como consecuencia de la desatención por la Administración de sus deberes para con los bienes integrantes del patrimonio histórico; y ha servido además para confirmar una tendencia judicial orientada a constatar la presencia constante de intereses comunes que justificarian la exigibilidad de una acción de todas las administraciones en esta materia.

Esta situación ha sido analizada, entre otras, en la sentencia del Tribunal Supremo de 17 de octubre del año 2010, cuyo objeto se vinculaba con una reclamación de responsabilidad patrimonial solidaria formulada por el fallecimiento de una persona, causada por el impacto de una piedra que procedía del castillo de Calatañazor. La reclamación de responsabilidad patrimonial se dirigía indistintamente frente al Estado, por el hecho de pertenecer al Patrimonio del Estado el citado castillo; frente a la comunidad autónoma, por sus competencias en materia de protección y conservación de bienes de interés cultural; $y$, frente al Ayuntamiento, titular de la calzada por la que caminaba al accidentado, imputándose a esta última Administración una omisión de vigilancia y conservación, que alcanzaría no sólo a la vía municipal, sino también a los elementos adyacentes a la misma.

Bajo tales parámetros, el Tribunal Supremo confirma la sentencia de instancia y a partir de datos como la titularidad no controvertida de los bienes, el traspaso de las funciones y servicios del Estado, en materia de cultura, a la comunidad autónoma, en el marco de las funciones relativas al patrimonio histórico-artístico, monumental arquitectónico y arqueológico de interés para la comunidad autónoma, concluye en una proclamación de responsabilidad patrimonial de aquellas dos administraciones.

En el caso de los ayuntamientos, esta responsabilidad se analiza en aquel supuesto a tenor del artículo 7 de la Ley del patrimonio histórico español, en relación con el artículo 25.2.e) de la Ley 7/1985, de 2 de abril, de bases de régimen local, y el deber de cooperación de aquellos con los organismos competentes para la ejecución de la LPHE en la conservación y custodia de dicho patrimonio comprendido en su término municipal. Sin embargo, rechaza dicha tesis el Tribunal Supremo al considerar que no puede equipararse el deber de colaboración en la custodia y conservación de los bienes que resulte para el Ayuntamiento, de carácter general, con el ejercicio de las concretas competencias que la Ley atribuye a la comunidad autónoma y a cuya deficiencia resulta imputable, en este caso, el resultado lesivo. Además, el citado deber de colaboración no excluiria en cualquier caso la responsabilidad propia de la comunidad autónoma.

Resulta igualmente relevante esta sentencia, como ya se apuntaba, a fin de conformar una base doctrinal acerca de la apreciación de una acción específica de las administraciones en materia de protección del patrimonio, que resulta común a todas ellas, al amparo de la doctrina constitucional (STC 17/2001, de 31 de enero), que identifica un genérico concepto constitucional de la cultura, integrado por todos aquellos bienes que por su naturaleza forman parte de la cultura de un pais y sobre los que concurririan competencias comunes del Estado y de las comunidades autónomas.

Manifestación de un signo diverso en este ámbito de responsabilidad frente a terceros se recoge en otras numerosas sentencias de nuestros juzgados y tribunales, que analizan en cada caso no sólo el alcance de esta responsabilidad con ocasión de la conservación, protección y mantenimiento de los bienes integrantes del patrimonio por parte de las administraciones, sino además en el marco del ejercicio de un cúmulo de deberes adyacentes o vinculados a los anteriores. Véase, a título de ejemplo, la sentencia que dicta el Juzgado de lo Contencioso-Administrativo número nueve de Sevilla, de 3 de marzo del año 2011, que desestimaba un recurso contencioso-administrativo formulado frente a la desestimación de una reclamación de responsabilidad patrimonial interpuesta ante la Dirección del Patronato de la Alhambra y el Generalife. El supuesto se refería a unos daños ocasionados en un vehículo de propiedad de la reclamante, estacionado en un aparcamiento habilitado por el Patronato para sus trabajadores. No existía prueba acerca de que el estacionamiento hubiere sido incorrecto; sin embargo, cuando el actor fue a recoger el vehículo al salir de trabajo por la noche lo encontró dañado.

El fundamento de tal reclamación atañe a la inactividad de la Administración demandada, como titular de la explotación del servicio de aparcamiento y su ineficacia en el cumplimiento de los deberes de vigilancia. La sentencia, sin embargo, desestima dicha pretensión indemnizatoria, a partir de la prueba practicada, pues si bien se acredita que los daños se produjeron en el aparcamiento destinado a los vehículos de los trabajadores, correspondia al actor acreditar que la Administración tenía el deber de vigilancia en el aparcamiento que cedia gratuitamente para uso exclusivo de los trabajadores $y_{1}$ en su caso, que el servicio no presentaba las condiciones adecuadas. Por lo demás, se toma igualmente en consideración la posible concurrencia de un elemento extraño que rompería el nexo de causalidad entre los daños reclamados y el funcionamiento del servicio público correspondiente, con lo que finalmente se concluía en la necesaria desestimación del recurso formulado.

\section{ALGUNAS CONCLUSIONES}

1. El patrimonio histórico debe configurarse como uno de los intereses jurídicos fundamentales de nuestro ordenamiento, según se desprende del tenor con el que se expresa el artículo 46 de la Constitución. Para ello, se hace preciso regular un conjunto de instrumentos de protección que, en gran parte, imponen deberes o cargas que exceden del cúmulo de facultades que generalmente integran la órbita del derecho de propiedad.

2. Lo expuesto suele traducirse en importantes restricciones al contenido normal del derecho de propiedad, que materialmente perjudican de un modo singular al titular de tales bienes o de 


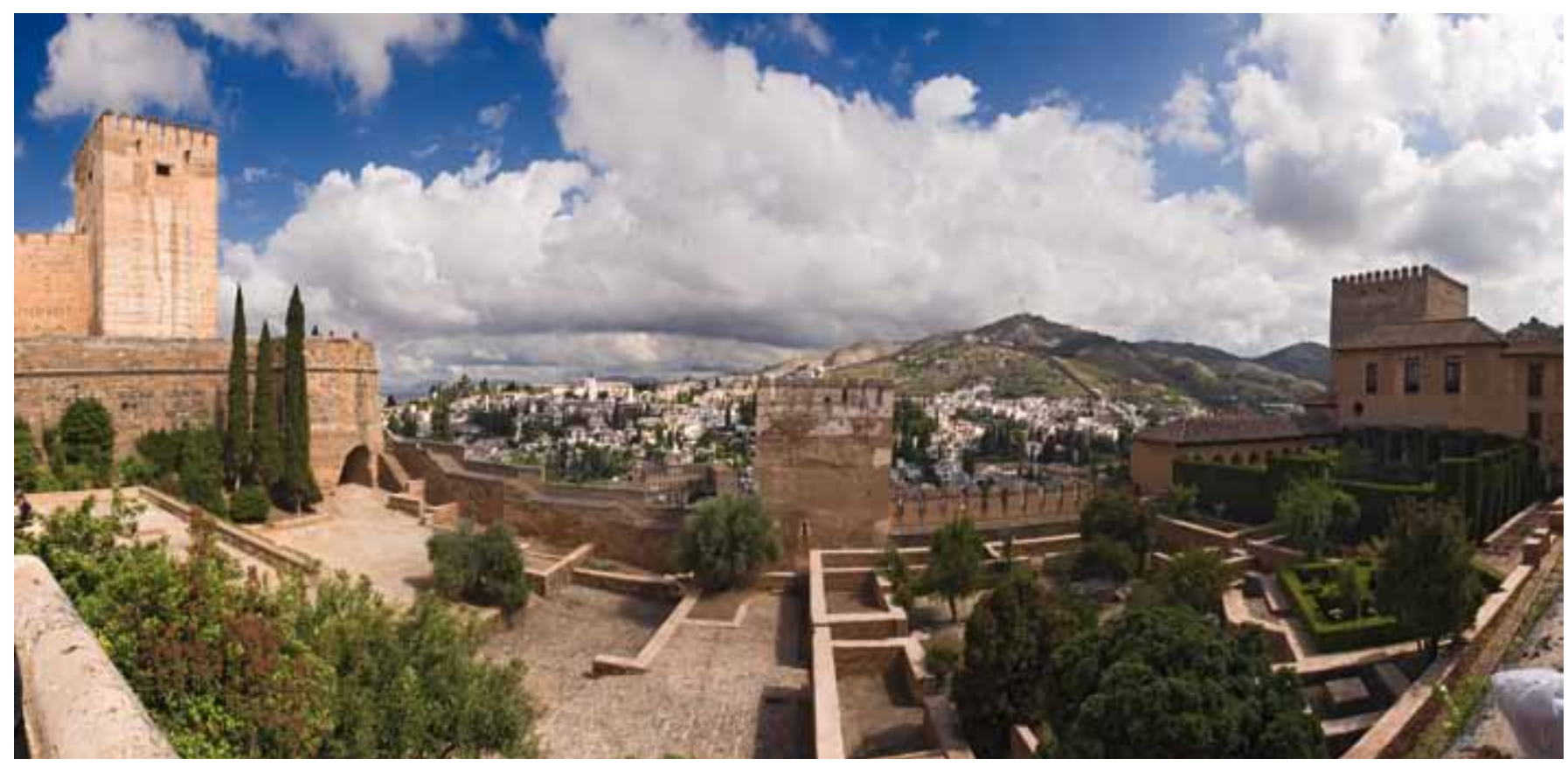

La reclamación de un trabajador de la Alhambra tras sufrir daños su coche aparcado dentro de las instalaciones del conjunto monumental fue desestimada por la responsabilidad del demandante de avisar del no cumplimiento de las obligaciones del personal de seguridad de las instalaciones. Foto: Fondo Gráfico IAPH Juan Carlos Cazallal

cualesquiera otros derechos relacionados con los mismos, haciendo surgir el deber de la comunidad de compensar dicho sacrificio, pues, en definitiva, se justifica éste en beneficio o interés de la generalidad.

3. La justificación de la situación descrita ha venido analizándose a partir de un principio fundamental, manifestación en este concreto ámbito de la proporcionalidad, cual es, el del justo equilibrio, cuya aplicación práctica se reconoce en muchas de las sentencias de nuestros tribunales y que lleva aún al Tribunal Supremo a realizar una auténtica proclamación de la aplicabilidad del sistema de responsabilidad general al ámbito de la protección del patrimonio histórico.

4. La aplicación del anterior sistema a la protección del patrimonio histórico exige la valoración en cada caso de los requisitos que con carácter general se exigen para apreciar un supuesto de esta naturaleza en cualquier otro ámbito propio de las administraciones públicas.

5. Así, la práctica de los tribunales viene a configurar el régimen de la responsabilidad patrimonial que se ofrece en este ámbito de un modo sustancialmente idéntico al propio del sistema general existente en la materia; esto es, se genera la responsabilidad patrimonial en todos aquellos supuestos en los que el administrado sufre una lesión patrimonial, consecuencia directa del obrar, correcto o no, de la Administración y, así, surge la procedencia de la indemnización.

6. Uno de los aspectos en los que vierte, en mayor medida, su eficacia la tesis descrita es el relativo a la definición del contenido esencial del derecho de propiedad mediante la imposición de importantes deberes que restringen sustancialmente las amplias facultades que tradicionalmente integran aquél; e impone el deber de resarcimiento por parte las administraciones públicas en orden a distribuir equitativamente entre la colectividad los perjuicios derivados de aquellas mayores cargas, cuya definitiva observancia se orienta, en conclusión, a la defensa y consecución de intereses generales.

7. Por último, la responsabilidad patrimonial de las administraciones en este contexto no sólo se despliega frente a los titulares de los bienes o derechos, sino también ante terceros, cuando éstos sufren daños y perjuicios derivados de la desatención por la Administración de sus deberes para con los bienes integrantes del patrimonio histórico.

\section{Bibliografía}

BERBEROFF AYUDA, D.; SOSPEDRA NAVA, F. J. (2006) Fundamentos dogmáticos de la responsabilidad patrimonial de la Administración en la jurisprudencia. Madrid: Colegio General del Poder Judicial, 2006 FERNÁNDEZ-CORREDOR SÁNCHEZ-DIEZMA, J. (2008) Patrimonio histórico. Urbanismo y responsabilidad patrimonial. Ceflegal: revista práctica de derecho. Comentarios y casos prácticos, n. ${ }^{9} 91,2008$, p. 115

LAMANA PALACIOS, J. (2009) Responsabilidad patrimonial del Estado por la conservación de los bienes del Patrimonio Histórico Español. Anales de la Abogacia General del Estado, n. ${ }^{\circ} 2007,2009$, pp. 305-317

MENÉNDEZ SEBASTIÁN, E. M. (2008) La función social de la propiedad y su repercusión en los supuestos indemnizatorios de la Ley 8/2007, de Suelo, y los espacios naturales protegidos. Justicia administrativa: Revista de derecho administrativo, n. ${ }^{\circ} 38,2008$, pp. 35-62 